\title{
Development of Measures to Reduce the Negative Impact of Sewage Sludge from Pulp and Paper Production
}

\author{
Kholudeneva A. O., Efremova S. Yu.
}

\begin{abstract}
The article analyzed the technogenic load of a pulp and paper mill as a source of waste generation. Based on the analysis, the waste groups of the pulp and paper industry with the excess of education standards were identified, and among these groups suitable for recycling and reuse. Among such wastes, osprey was isolated - waste from the processing of sewage sludge from the pulp and paper industry. The stages of the technological process of manufacturing pulp and paper products from recycled materials were also considered. An analysis of scientific and technical information was carried out, within the framework of which the features of the main technical solutions in the field of processing and disposal of osprey were investigated. An electro-osmotic plant was developed, the essence of which is to achieve maximum energy efficiency in the process of dewatering sewage sludge from the pulp and paper industry. According to the results of the experiments, a correlation assessment was made of the parameters of electroosmotic dehydration: reduction of the residual mass of the osprey and current strength on the plant plates during electroosmosis, from which it follows that the values of the cross-correlation coefficient are significantly affected by the electric field strength of the electroosmosis.
\end{abstract}

Keywords : electroosmosis, sewage sludge from pulp and paper products, analysis of technogenic load, waste, dehydration.

\section{INTRODUCTION}

Currently, it is extremely urgent to reduce the negative impact of industrial enterprises on the environment and the efficient use of resources. Due to the fact that Russia has significant timber resources, the leading sectors of the national economy include, among others, the pulp and paper industry. A large volume of products both in Russia and abroad causes a significant need. Based on this, the aim of the scientific work is to develop mechanisms to reduce the negative impact of pulp and paper enterprises on the environment. To achieve this goal, it is necessary to perform a number of tasks: to analyze the technogenic load of the pulp and paper mill as a source of waste generation, identify waste groups of the pulp and paper industry that exceed the educational standards, determine the waste suitable for processing and reuse, and consider the stages of the manufacturing process pulp and paper products from recycled materials, to study the features of the main technical solutions in the field of processing and disposal waste of pulp and paper enterprises, to consider the possibility of improving the energy efficiency of waste processing through the introduction of technical innovations.

By analyzing the technogenic load of the pulp and paper mill as a source of waste generation, the following conclusions can be drawn. Approximately $99 \%$ of the waste from the pulp and paper industry belongs to class V, $2 \%$ belongs to class IV, the share of waste from the remaining III, II, I hazard classes of waste is less than $1 \%$. Exceeding the standards for waste generation have:

- pulp processing waste,

- paper break,

- scrap

- aluminum waste unsorted,

- waste mineral transmission oils,

- waste mineral mineral oils.

Taking into account the processed statistical data, $23 \%$ of waste is transferred to landfills, $26 \%$ is reused at enterprises, the largest amount of waste from enterprises is transferred to other organizations - $51 \%$.

Pulp and paper mills have wastes that can be reused:

- "Cellulose processing waste" (in most cases, it is taken to landfills):

- "Wastes from the treatment of sewage sludge" (transferred for use to third parties).

As a result of the analysis of statistical data on the technogenic load of enterprises, as a source of waste generation, it was revealed that the norm for the generation of the following wastes was exceeded:

- "Cellulose processing waste" - is generated 7-14\% more than the standard value, hazard class $\mathrm{V}$ (cellulose processing waste is fibrous waste of various fractions and composition, in particular fine and coarse fiber waste, which contain glue impurities that cannot be used in paper production, this waste is currently being transferred to landfill for landfill);

- "Waste of mineral mineral oils", is generated by $28-32 \%$ more than the normative value, hazard class III (the composition of the waste includes oil products, sulfur, mechanical impurities, additives; this waste is significantly higher than the production standard, is moderately hazardous, reuse on pulp is impossible for a paper company, a license is required for its disposal).

Revised Manuscript Received on October 15, 2019.

* Correspondence Author

Kholudeneva, A. O., Federal State Budgetary Educational Institution of Higher Education "Penza State Technological University"

Efremova, S. Yu., Federal State Budgetary Educational Institution of Higher Education "Penza State Technological University" 
Pulp and paper mills also generate large quantities of "Wastewater sludge processing waste" (scum), hazard class $\mathrm{V}$ in the amount of $7-14 \%$ above the standard values (the waste consists of water, short pulp fibers; this waste is temporarily stored in enterprise, and then transferred to a landfill for landfill).

In this regard, the most attention should be paid to two wastes: "Pulp processing waste", which currently exceeds the waste generation standards, is transferred for disposal to the landfill, and its components are not used as potential secondary resources at the enterprise; "Wastewater sludge processing waste", which produces a fairly large amount, but is also not used by the enterprise.

Therefore, it is further worth considering the issues of disposal, sorting and reuse of paper pulp waste.

Today, pulp and paper production is increasingly focused on the use of recycled materials in the technological process, so in 2015 the use of waste paper in the pulp and paper industry amounted to $24.7 \%$ of the total volume of raw materials used, and by 2018 , the share of recycled materials in the technological the process increased to $27.6 \%$ [5]. On the territory of the Russian Federation there are about 30 enterprises using waste paper for the production of paper and cardboard.

The technological process for the manufacture of pulp and paper products from recycled materials includes the following stages: preparation of waste paper (dissolving in a pulper with the extraction of synthetic polymer waste, subsequent sorting with the release of small fractions of polymers, metal impurities, other contaminants), supplying the cleaned waste paper to paper making machine, molding, sizing, drying, rolling and finishing of the finished paper web. In the process of forming paper pulp and washing technological equipment, a runoff is formed with a high content of suspended solids (a fine fraction of waste paper), which will form a large amount of sediment - osprey, consisting of $90 \%$ waste paper and $10 \%$ mechanical impurities.

Samples of osprey formed during the wastewater treatment of pulp and paper production, which is a typical representative of the industry, were taken for research.

Since osprey is a heavily watered product (humidity of about $80 \%$ ) that is difficult to process, studies were carried out at the first stage to increase the efficiency of its dehydration.

Based on the analysis of scientific and technical information [2, 3, 4] it was found that dehydration can be implemented by mechanical and thermal methods. Among the methods of mechanical dehydration in industrial practice are widespread: filter - presses, vacuum filters, squeezers, centrifuges and precipitation apparatus of various designs. Thermal methods are less often implemented in practice due to the high capital and operating costs and the complexity of the process. Thermal dewatering of the osprey can be implemented in the second stage after preliminary mechanical dewatering, while the process can be carried out in drying plants of various designs (conductive, convective (spray, pneumatic, fluidized bed dryers) and drum dryers.

Theoretical studies on the selection of the optimal technological solution for handling osprey taking into account environmental, economic, technological criteria. During the analysis, it was found that biological, thermal and mechanical methods can be used for processing and neutralizing osprey (Figure 1).

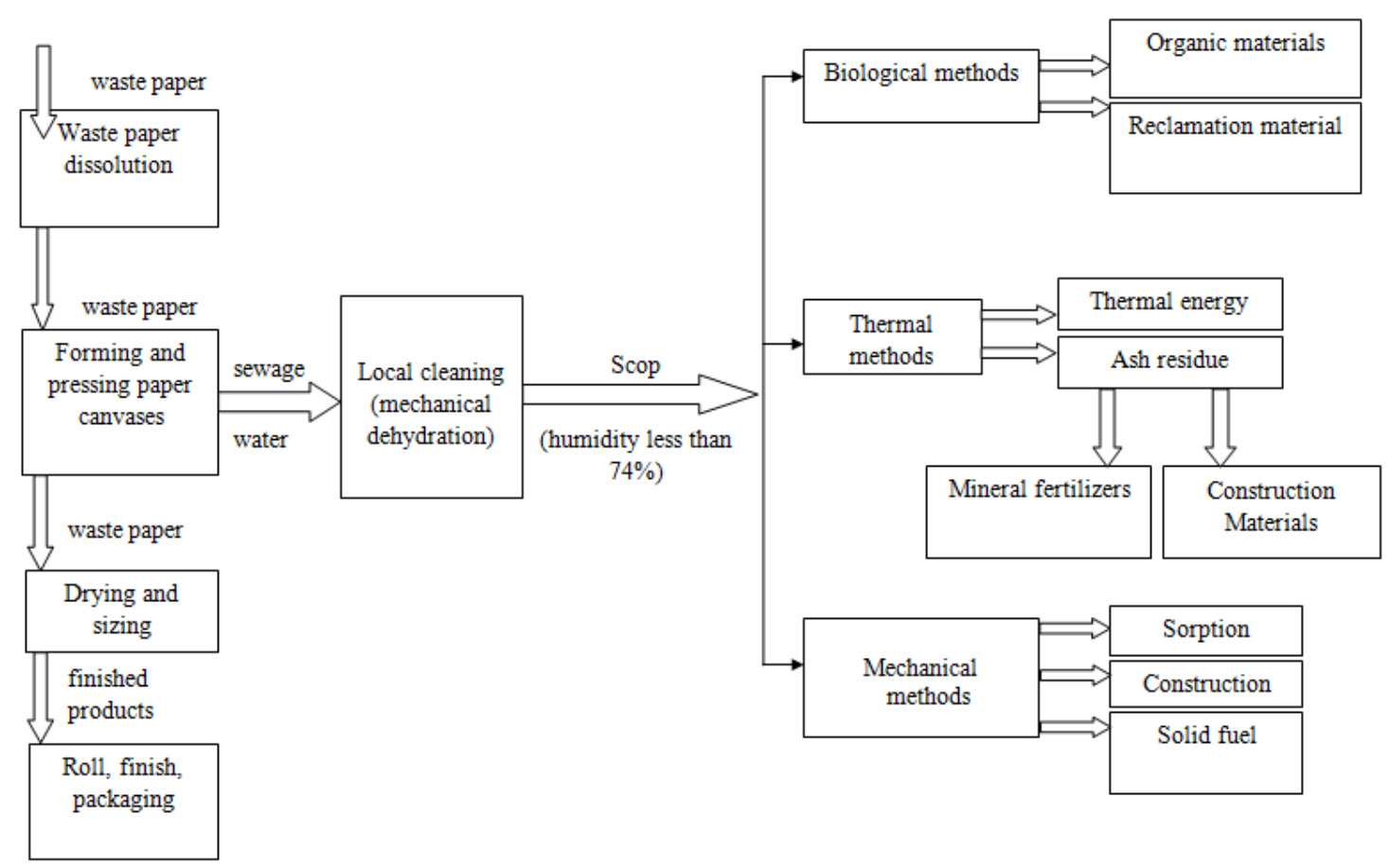

Figure 1. The main technological solutions in the field of processing and disposal of osprey 
Since the osprey mainly contains organic components and a small amount of nutrients, it can potentially be processed by field composting in piles. As a result of the fact that the osprey contains a small amount of biogenic components, it is recommended that it be composted in a mixture with biodegradable wastes, for example, bark and wood wastes generated during debarking of wood at pulp and paper plants. Bark wood waste contains humus, lignin, have high porosity and moisture capacity, as well as a high content of organic substances. Also, bark and wood waste contains nitrogen, which serves as a source of nutrition for plants. In addition, the process can be intensified by the application of mineral and organic fertilizers.

Osprey dehydrated on vacuum filters can be thermally neutralized by burning in furnaces of various designs. In this case, an ash residue will be obtained as a by-product, and the heat generated during the thermal process can be used for production purposes. Since the osprey is characterized by high ash and high humidity, it is advisable to burn it in a mixture of bark and wood waste generated during debarking of wood. The fuel mixture can be supplied for neutralization in bulk or used for the production of fuel briquettes.

In addition, known technologies for the use of osprey in the production of building materials.

Osprey can be used as a component of concrete mix, increasing its workability; as a burnable additive in the manufacture of ceramic bricks, upon receipt of dry gypsum plaster, as an additive to the mixture for insulation boards, in the production of building blocks and finishing materials. The advantage of using osprey in the production of building materials is the saving of primary resources [5].

Since osprey has sorption properties, it can be used for the production of sorption products. To give the sorbent antibacterial properties and reduce flammability, it is recommended to use various additives (for example, borax, flame retardant, etc.) [6]. Based on the theoretical studies [4, $5,6]$, taking into account environmental, economic and technological criteria, it was found that the most rational direction for handling the osprey is its electroosmotic dehydration using a technical innovation in the form of an electroosmotic installation for further use.

The purpose of further research is to obtain an economic and technical justification for the use of electroosmotic dehydration of paper-produced wastes, obtain general information about dehydration methods, and identify their comparative characteristics.

With the help of electroosmotic dehydration, experiments show that it was possible to reduce the humidity of the waste by $70 \%$ with minimal energy consumption.

Next, we move on to a more detailed study of the mechanisms for reducing the moisture content of sewage sludge from the pulp and paper industry.

To organize research, an electroosmotic installation was developed, the essence of which is to achieve maximum energy efficiency of the dehydration process. Figure 2 schematically shows the device of an electroosmotic installation, where 1 is a housing made of insulating material; 2 - movable electrode; 3 - fixed electrode with perforation; 4- top cover with thread for screw 5, which regulates the initial compression pressure of the osprey (6). An electric voltage (electric current) is supplied to the

electrodes (2) and (3) through the wires (7) and (8), which provides the necessary electric field strength, causing effects of variation in the particle velocity, 9 - perforation in the housing around the entire perimeter, which ensures additional convective dehydration after completion of the electroosmosis process when lifting the electrode (2), 10 external regulator of the angle of inclination of the housing, providing convection dehydration of the lower layers of the mass after completion of the electroosmosis process, 11- and olyatsionny sump for collecting the separated moisture.

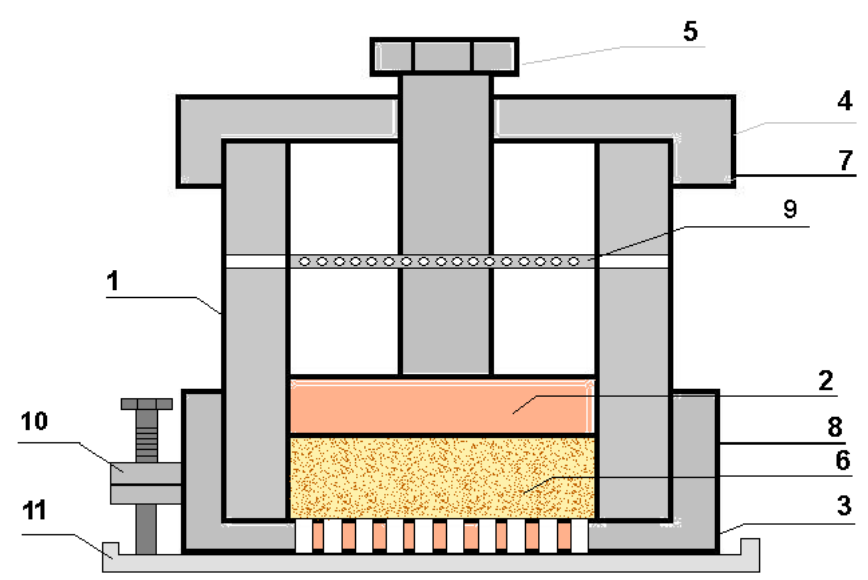

Figure 2 - Laboratory electroosmotic installation

The above technical solution allows for the most energy-efficient process of electroosmotic dehydration compared to the level of technology that promotes dehydration without additional energy costs.

From the experimental data obtained in laboratory conditions, it can be noted that, as the dehydration occurs under the influence of electroosmosis, there is a discrepancy between the rate of decrease in mass $(\mathrm{m}(\mathrm{t}))$ of the osprey and the values of the electric current $(i(t))$ flowing between the plates of the laboratory electroosmotic installation. This fact indicates that the relationship of these processes is characterized by cross-correlation (cross-correlation coefficient ), which varies with time. This indicates the influence on the drying process, not only the effect of electroosmosis, but also other related factors. It is of scientific and applied interest to study the dependence on the voltage $\mathrm{U}$ between the plates of the installation (on the electric field strength).

Using these data, it seems possible to establish the time intervals for the dewatering of sewage sludge from the pulp and paper industry, characterized by specific values of the coefficient that would indicate the onset and continuation of the effects of processes accompanying electroosmosis that affect $\mathrm{m}(\mathrm{t})$. In this case, it is necessary to additionally take into account the dependence on the electric field strength between the plates of the laboratory setup, and in real conditions between the plates of the production plant.

To evaluate $r_{i, m}\left(\tau_{k}\right)$ in stages (at various time intervals), you should use the following algorithm 


$$
r_{i, m}\left(\tau_{k}\right)=\frac{k_{i, m}\left(\tau_{k}\right)}{\sigma_{i}\left(\tau_{k}\right) \cdot \sigma_{m}\left(\tau_{k}\right)}
$$

where $k_{i, m}\left(\tau_{k}\right)$ - is the correlation moment of two random variables $i(\tau)$ and $m(\tau)$;

$\sigma_{i}\left(\tau_{k}\right)$ and $\sigma_{m}\left(\tau_{k}\right)$ - the root mean square values of the electric current of the electroosmosis process and the mass of sewage sludge over a time interval $\left[0 ; \tau_{k}\right]$.

In expanded form (1) can be represented as

$r_{i, m}\left(\tau_{k}\right)=\frac{1}{k\left(\tau_{k}\right)} \cdot \sum_{k=1}^{k\left(\tau_{k}\right)} \frac{\left(i_{k}-\bar{i}_{k}\right)\left(m_{k}-\bar{m}_{k}\right)}{\sigma_{i}\left(\tau_{k}\right) \cdot \sigma_{m}\left(\tau_{k}\right)}$

Table 1 - Experimental values of mass and current strength at $\mathrm{U}=8 \mathrm{~V}$

\begin{tabular}{|l|l|l|l|l|l|l|l|}
\hline$t_{j}$ [hour] & 0 & 0,25 & 0,5 & 0,75 & 1 & 1,25 & 1,5 \\
\hline$i_{j}$ [A] & 1,75 & 1,3 & 0,9 & 0,9 & 0,8 & 0,8 & 0,75 \\
\hline$m_{j}$ [gram $]$ & 70 & 59 & 51 & 46 & 40 & 35 & 32 \\
\hline$t_{j}$ [hour] & 1,75 & 2 & 2,25 & 2,5 & 2,75 & 3 & 3,25 \\
\hline$i_{j}$ [A] & 0,75 & 0,65 & 0,6 & 0,55 & 0,5 & 0,4 & 0,2 \\
\hline$m_{j}$ [gram $]$ & 28 & 26 & 25 & 24 & 24 & 24 & 23 \\
\hline
\end{tabular}

Table 2 - Experimental values of mass and current strength at $\mathrm{U}=16 \mathrm{~V}$

\begin{tabular}{|c|c|c|c|c|c|c|c|c|c|}
\hline$t_{j}[$ hour $]$ & 0 & $\begin{array}{l}0,2 \\
5\end{array}$ & 0,5 & 0,75 & 1 & 1,25 & 1,5 & 1,75 & 2 \\
\hline$i_{j}[\mathrm{~A}]$ & $\begin{array}{l}3,7 \\
5\end{array}$ & 2,6 & 1,2 & 0,6 & 0,6 & 0,5 & 0,4 & 0,2 & 0,1 \\
\hline$m_{j}$ [gram] & 70 & 52 & 45 & 40 & 32 & 28 & 24 & 23 & 23 \\
\hline
\end{tabular}

Table 3 - Experimental values of mass and current strength at $\mathrm{U}=24 \mathrm{~V}$

\begin{tabular}{|l|l|l|l|l|l|l|l|}
\hline$t_{j}$ [hour] & 0 & 0,16 & 0,33 & 0,5 & 0,66 & 0,83 & 1 \\
\hline$i_{j}$ [A] & 2,5 & 1,63 & 1,21 & 0,8 & 0,53 & 0,31 & 0,09 \\
\hline$m_{j}$ [gram $]$ & 70 & 48 & 38 & 35 & 32 & 29 & 27 \\
\hline
\end{tabular}

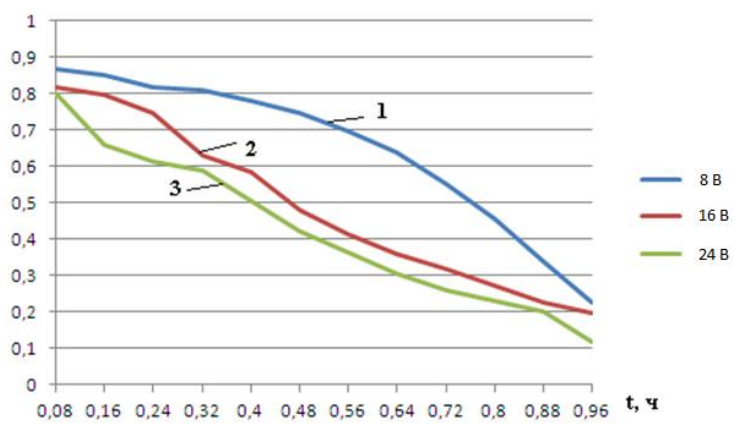

Figure 3 - Graphs of calculation results with voltage variation $\mathrm{U}$
From the calculations it follows that the values are significantly affected by the electric field intensity of the electroosmosis: the greater the intensity, the shorter the interval of significance in the drying process of the osprey. In this case, the non-linear nature of the dependence on tension is clearly visible, which allows you to choose the most rational value of tension: from a certain value of tension, it changes slightly. In our case, $\mathrm{U}=16 \mathrm{~V}$ gives almost the same effect as $24 \mathrm{~V}$. This means that a certain value of tension (not high - safe for the operator) should be stopped. The voltage on the plates of the installation easily translates into tension.

From the data in tables 1-3 and the graph (Figure 3), it follows that at low electric field strength, drying of the osprey occurs due to electroosmosis, because over $72 \%$ of the drying time $>0.5$. When the field strength is doubled, the same value is maintained for $30 \%$ of the drying time. With an increase in tension by 3 times, such a length is $\approx 20 \%$ of the total drying time.

Thus, from the calculations and graphs it follows that the processes associated with electroosmosis at high tension, compared with electroosmosis, make up a longer part of the drying time. Having values , it is possible to assess the degree of influence of the accompanying processes on drying and to determine the time of the relationship between electroosmosis and the associated processes initiated by it.

Thus, as part of the study, an analysis was made of the technogenic load of the pulp and paper mill as a source of waste generation. Based on the analysis, the waste groups of the pulp and paper industry with the excess of education standards were identified, and among these groups suitable for recycling and reuse. Among such wastes, osprey was isolated - waste from the processing of sewage sludge from the pulp and paper industry. The stages of the technological process of manufacturing pulp and paper products from recycled materials were also considered, including the stage that is especially relevant for the study, associated with the formation of runoff with a high content of suspended solids. An analysis of scientific and technical information was carried out, within the framework of which the features of the main technical solutions in the field of processing and disposal of osprey were investigated.

As part of the study, an electro-osmotic installation was developed, the essence of which is to achieve maximum energy efficiency in the process of dewatering sludge from the pulp and paper industry. According to the results of the experiments, a correlation assessment was made of the parameters of electroosmotic dehydration: a decrease in the residual mass of the osprey and current strength on the plant plates during electroosmosis, from which it follows that the values of the cross-correlation coefficient are significantly affected by the electric field strength of the electroosmosis: the higher the voltage, the shorter interval of significance in the drying process of the osprey. Thus, according to the results of the analysis, it can be argued that the processes associated with electroosmosis (convection dehydration, mechanical impact by pressing, heat generated by the electric current of the installation) at high tension make up a longer part of the dehydration time compared to electroosmosis. 


\section{REFERENCES}

1. The official website of the Federal State Statistics Service (Rosstat) http://www.gks.ru/

2. Ryzhakov V.V., Kupryashin V.A., Kholudeneva A.O. Features of the technology for the recycling of paper production based on the use of electroosmosis. Scientific and technical magazine "Defense complex - to the scientific and technological progress of Russia". M.: VIMI, 2013. No. 1. S.40-43

3. Ryzhakov V.V., Kholudeneva A.O. The results of studies of the characteristics of the market of insulation and their use in the organization of production of Ecoplit. Scientific and technical magazine "Defense complex - to the scientific and technological progress of Russia". M. VIMI, 2013. - No. 4. S.60-62

4. Chernyakhovskaya T. N. Marketing activity of the enterprise. Theory and practice. - M: Higher education, 2008 - 536s.

5. The concept of long-term socio-economic development of the Russian Federation for the period until 2020 (approved by order of the Government of the Russian Federation of August 8, 2009 N 1121-p.) Electronic fund of legal and scientific and technical documentation. http://docs.cntd.ru/document/902130343

6. The list of priority areas for the development of science, technology and technology of the Russian Federation (approved by Decree of the President of the Russian Federation of July 7, 2011 No. 899) Electronic fund of legal and scientific and technical documentation. http://docs.cntd.ru/document/902287707

7. Ryzhakov V.V., Kholudeneva A.O., Ryzhakov M.V. Investigations of the correlations of the processes of electroosmosis and related Interdisciplinary scientific and technical journal "Defense complex - to the scientific and technological progress of Russia". 2015.- No. 3 (127). . - M .: VIMI. - S. 41-43.

8. Ryzhakov V.V., Kholudeneva A.O., Ryzhakov M.V. Factors affecting environmental safety and the efficiency of the process of making eco-plates Scientific and methodological journal "XXI Century: Results of the Past and Problems of the Present Plus": Periodical scientific publication, series "Ecology". - Penza: Publishing House Penz. state technol. University, 2014. - No. 05 (21). S. 104-108 